AC 2011-1041: USING PEN-BASED TABLET PC TECHNOLOGY TO IMPROVE INSTRUCTION IN ENGINEERING ECONOMICS

Bruce V. Mutter, Bluefield State College

Bruce V. Mutter is the founder and CEO of the Center for Applied Research \& Technology, Inc. (CART) and teaches project management and engineering economics at Bluefield State College as an Associate Professor in the School of Engineering Technology. 


\title{
Using Pen-Based Tablet PC Technology to Improve Instruction in Engineering Economics
}

\begin{abstract}
A Center for Applied Research and Technology, (CART), Inc. worked with the School of Engineering Technology and Computer Science (SET) at a small College to implement a more active learning environment for teaching a junior-level engineering economics course (ENGR 315). Using a pen-based Tablet PC coupled with the CART CMS, a Moodle ${ }^{\circledR}$-based course management service and interactive software, our instructional approach was modified to convert the traditional lecture-based ENGR 315 course to a more student-centered live learning environment.
\end{abstract}

This method is now being planned for introductory mathematics and advanced computer science courses. Results show that the use of pen-based Tablet PC's coupled with live capture of the lecture posted on the CART CMS have resulted in better student retention and improved attention during the course. There is evidence of improved student performance in faculty evaluations.

Using the Tablet PC instead of whiteboards, overheads, and blackboards allowed the ENGR 315 instructor to: (1) face students naturally and continually while solving equations; (2) produce cash flow diagrams more precisely and efficiently; (3) eliminate interruptions and distractions caused by physical transitions between whiteboard and projector screen; (4) quickly introduce color during live presentations that further improve understanding of concepts and classroom discussions; (5) facilitate student note taking through CART CMS posts that improve organization and elaboration; (6) accommodate student review for tests and quizzes; (7) provide students with a ready-made, savable, printable, portfolio useful for Fundamentals of Engineering (FE) review and exam preparation, and (8) work more high-quality problem examples due to these increased course delivery efficiencies.

\section{Background}

ENGR 315 -Engineering Economics is a three credit hour course that does not incorporate a formal laboratory (3-0-3). At our college it is described as the study of the relative economy of engineering alternatives, compound interest in relation to calculation of annual costs, present worth and prospective rates of returns on investments, methods of depreciation, sinking cost, increment cost, general studies with emphasis on retirement and replacement of equipment, consideration of taxes, public works, and manufacturing costs as related to economic solutions of engineering proposals. Principles of engineering ethics are presented as related to cost analysis.

With a prerequisite of completed sophomore standing, ENGR 315 is a junior-level course for all our School of Engineering Technology (SET) Bachelor of Science majors that include:

- Architectural Engineering Technology

- Civil Engineering Technology

- Computer Science 
- Electrical Engineering Technology

- Mechanical Engineering Technology

- Mining Engineering Technology

Some of the specific ENGR 315 content areas of interest for the application of pen-based tablet PC technologies in improving instruction included:

- Illustrating the Time-value of Money

- Comparing Compound Interest Formulas \& Factor Tables

- Diagramming Cash Flows

- Conceptualizing Equivalency and Effective Interest Rates (\%)

- Analyzing the Present (PW), Annual (AW), \& Future Worth (FW) of Alternatives

- Analyzing Rate-of-Return (ROR) \& Benefit/Cost (B/C) of Alternatives

- Analyzing Challenger (Emerging) vs. Defender (Baseline) Technologies

- Understanding Inflation \& Depreciation

- Studying Ethics \& Global Awareness Cases with Questionnaires, and Rubrics

- Learning Life-long Lessons through Personal Finance Examples

- Reviewing Fundamentals of Engineering (FE) Exam Questions

\section{Introduction}

Based on feedback from our students, the Center for Applied Research and Technology, (CART), Inc. at our college wanted to work with School of Engineering Technology and Computer Science (SET) to implement a more active learning environment for teaching a juniorlevel engineering economics course (ENGR 315). The instructor used a pen-based Tablet PC coupled with the CART CMS, a Moodle ${ }^{\circledR}$-based course management service and interactive software, and the instructional approach was modified to convert the traditional lecture-based ENGR 315 course to a more student-centered live learning environment.

\section{Process}

The key elements of changing the instructional approach to the course involve the following principle process and steps:

- Transferring www.cartinc.com updates of the CMS to college course servers

- Setting up the Moodle®-based CMS for both Hybrid and Online Course Delivery

- Opening each live classroom session with projected Windows Journal ${ }^{\circledR}$ Templates (.JTP)

- Solve problems in live classroom setting with student input, discussions and mini-labs

- Overwrite the Template (.JTP) file and save lectures as Windows Journal Notes (.JNT)

- Edit or augment the Windows Journal Note (.JNT) file immediately following the session

- Convert and save the lecture corrected Note file as a .PDF following review and edit

- Post the converted .PDF on CMS as i.e. "ENGR 315 - Lecture Notes -26 October 2010"

- Review the posted .PDF as an accessible resource for students and instructors

In this screenshot shown in Figure 1 below, ENGR 315 problems referenced from the textbook are solved in live sessions on a tablet PC and the saved file is posted on the Moodle ${ }^{\circledR}$-Based CMS course site for later review. 


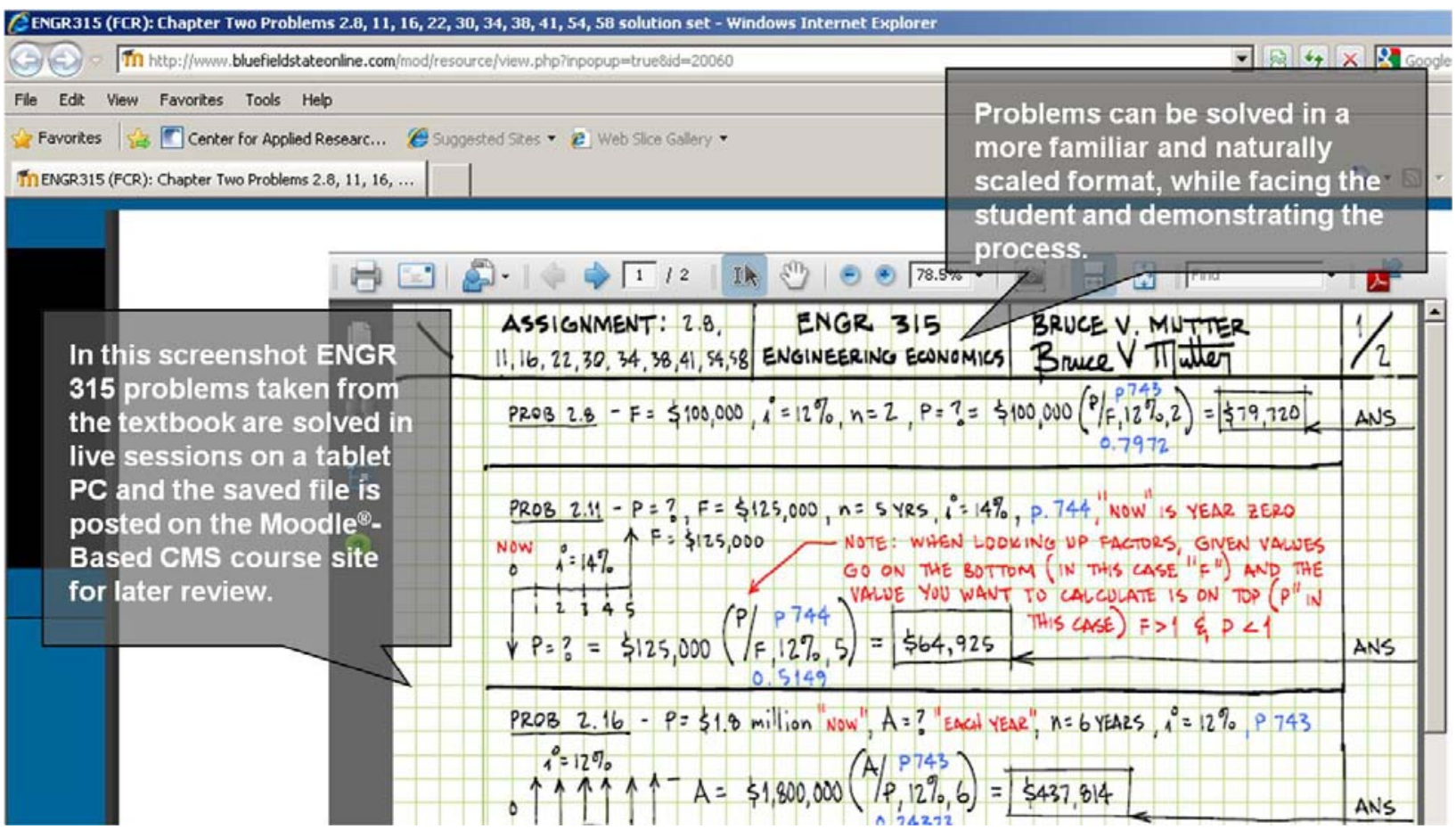

Figure 1 - ENGR 315 - CMS Screenshot

As a result, problems can be solved in a more familiar and naturally scaled format, while facing the student and demonstrating the process. In addition, pen-Based technology allows the instructor to mix solutions by hand with Excel ${ }^{\circledR}$ spreadsheet function demonstrations and compare the results side-by-side as shown in Figure 2 below.

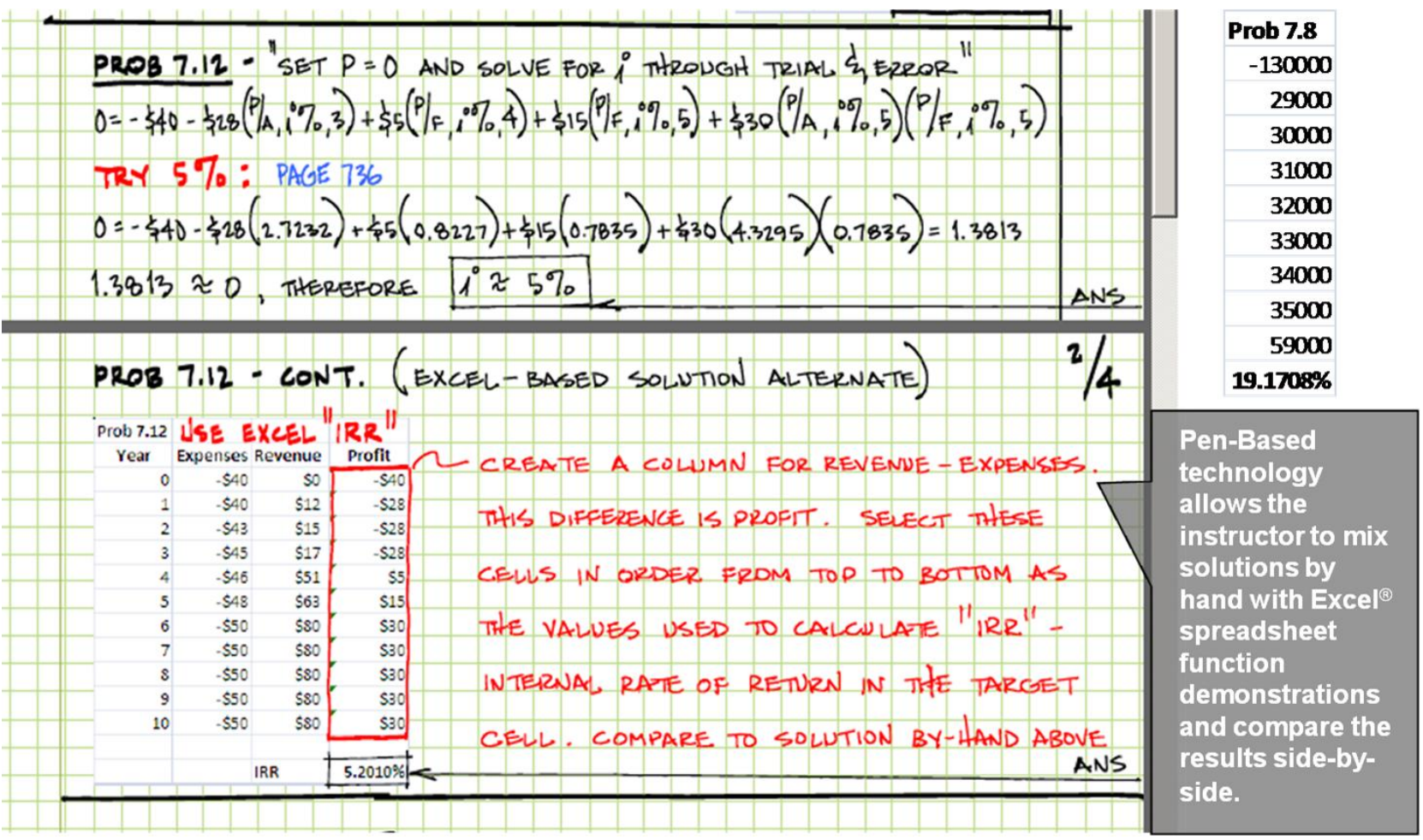

Figure 2- ENGR 315 - Excel Solution Integration 


\section{ENGR 315 Course Evaluations}

Overall student evaluations for past ENGR 315 course deliveries did not generate particularly low numbers. However, the Learning Outcomes summary for the Fall Semester 2008 (See Figure 3) was 3.98 on a 5.00 point scale. This illustrates room for improvement in certain areas.

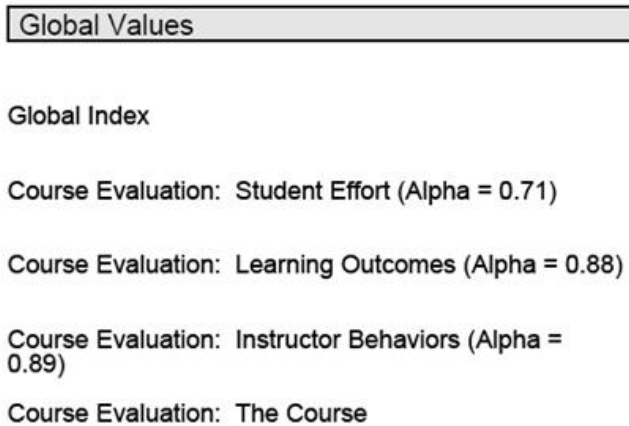

Global Index

Course Evaluation: Student Effort $($ Alpha $=0.71)$

Course Evaluation: Learning Outcomes $($ Alpha $=0.88)$

Course Evaluation: Instructor Behaviors (Alpha = $0.89)$

Course Evaluation: The Course
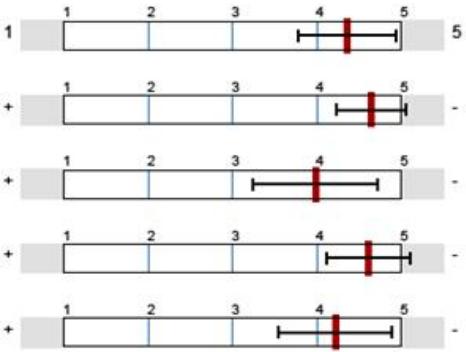

\section{Legend}

Question text

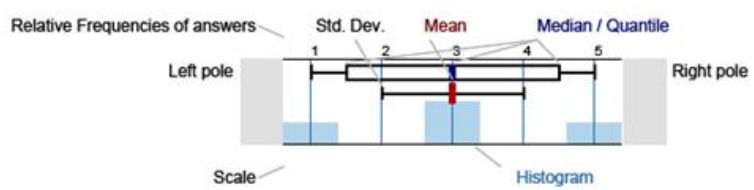

Figure 3 - ENGR 315 Course Evaluation Fall Semester 2008

As shown in Figure 4 below, some improvement in student evaluations can be measured following implementation of the process described earlier. For example, the overall course evaluation improved from 4.22 for fall semester 2008 to 4.68 for fall 2009 on a 5.00 point scale.

\begin{tabular}{|c|c|c|c|c|}
\hline Global Values & & & & \\
\hline & MGrd FGrd & & & \\
\hline Global Index & & $4 \quad 5$ & 5 & $\begin{array}{l}\text { av }=4.55 \\
\text { dev }=0.61\end{array}$ \\
\hline LEARNING (Alpha $=0.88)$ & $=\frac{\bar{B}}{B}$ & 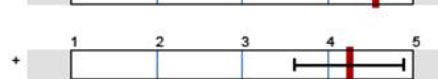 & & $\begin{array}{l}\text { av }=4.25 \\
\text { dev }=0.76\end{array}$ \\
\hline ENTHUSIASM $($ Alpha $=0.94)$ & $\bar{F} \stackrel{\hat{F}}{A}$ & 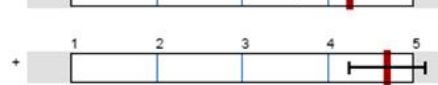 & & $\begin{array}{l}\text { av }=4.69 \\
\text { dev }=0.53\end{array}$ \\
\hline ORGANIZATION (Alpha $=0.87$ ) & $=\frac{B}{B}$ & $+\quad i^{1}{ }^{2}$ & & $\begin{array}{l}\text { av }=4.52 \\
\text { dev }=0.65\end{array}$ \\
\hline GROUP INTERACTION (Alpha $=0.99)$ & $=\frac{\frac{D}{B}}{C}$ & $z^{5}$ & & $\begin{array}{l}\text { av }=4.6 \\
\text { dev }=0.68\end{array}$ \\
\hline INDIVIDUAL RAPPORT (Alpha $=0.97$ ) & $=\frac{B}{A}$ & ${ }^{4} \square^{5}$ & & $\begin{array}{l}\text { av }=4.83 \\
\text { dev }=0.39\end{array}$ \\
\hline BREADTH $($ Alpha $=0.96)$ & $-\frac{\bar{B}}{A}$ & 口告 & & $\begin{array}{l}\text { av }=4.6 \\
\text { dev }=0.51\end{array}$ \\
\hline EXAMINATIONS $($ Alpha $=0.87)$ & $=\frac{A}{B}$ & +\begin{tabular}{|l|l|l|} 
& 2 & 3 \\
& & \\
\end{tabular} & & $\begin{array}{l}a v=4.68 \\
\text { dev }=0.59\end{array}$ \\
\hline ASSIGNMENTS $($ Alpha $=0.76)$ & $\bar{D} \frac{A}{B}$ & +\begin{tabular}{|l|l|l|l|} 
& 2 & 3 \\
& & 1 & \\
\end{tabular} & & $\begin{array}{l}\text { av }=4.15 \\
\text { dev }=0.88\end{array}$ \\
\hline OVERALL (Alpha = 0.96) & $=\Delta$ & $+\quad$\begin{tabular}{l|l} 
& 2 \\
&
\end{tabular} & & $\begin{array}{l}\text { av }=4.68 \\
\text { dev. }=0.49\end{array}$ \\
\hline
\end{tabular}

Figure 4 - ENGR 315 Course Evaluation Fall Semester 2009 


\section{Instructor Observations}

While using the Tablet PC is not a new concept, it has proven particularly beneficial for illustrating ENGR 315 problem solutions when paired with projection in the classroom. Initial assessments demonstrate that using this approach in lieu of whiteboards, overheads, and blackboards allowed for a number of improvements to be observed in the delivery of ENGR 315.

(1) Improved Student-Instructor Rapport - By facing students naturally and continually while solving equations, the instructor encourages communication and questions with a more connected and engaged student. Solving problems together in the same format required by the instructor for assignment submission develops reciprocity, supports cooperation, and students gain confidence that they can duplicate the process outside of the classroom. In turn, the improved rapport encourages a more active learning environment with more prompt feedback, correction, and interaction. Awareness of time-on-task can be emphasized. For example, the Windows clock is on display to both the instructor and the student throughout the session. Higher expectations are communicate through demonstrations that better duplicate the nature of subsequent assignments in real-time. Alternative solutions can be explored side-by-side that better respect diverse talents and different learning styles. For example, most ENGR 315 problems can involve and compare solutions by algebraic formulas, compound interest factors, Excel ${ }^{\circledR}$-based solutions, online calculators, and “trial-and-error” versus table interpolation. These comparisons can take place on one coordinated projected screen display without unnaturally and unnecessarily speeding up the pace in the classroom.

According to recent research published in Communication Education which examined the relationships between instructors and students in building positive relationships and the overall classroom environment. "It is important for instructors to build rapport in the classroom because it has behavioral, relational, and cognitive implications, with students participating more, building relationships with their fellow students, and reporting more learning," said Brandi Frisby of West Virginia University, one of the authors of the study. "When students experience more rapport and connectedness in the classroom, they are more likely to stay in school and experience academic success.”

This study appears in volume 59 (April 2010) of Communication Education, a publication of the National Communication Association. More information about NCA and its journals are available at http://www.natcom.org/.

It is perhaps worth noting that two of three students with deficient mid-term grades were retained (See Figure 4). One student reported that being able to review the lecture notes online allowed him to "catch up" and raise a "D” at mid-term to a low “B” final grade.

We should also clarify the ENGR 315 students do not typically use a Tablet PC in the classroom. While a few students have them, tablets are not required by our College or the School and their use is not yet significant beyond application by a few instructors. "Live capture" of the lecture has been accomplished through the utilization of Camtasia Studio 7.0® paired with Windows Journal ${ }^{\circledR}$ projected in the live classroom. This allows for replay of video solutions accompanied with an audio file description of the animation. This is an improvement over the use of more 
static Power-point ${ }^{\circledR}$ slide annotations, which are still used for some examples. An important self-criticism of the process described thus far is that we have not yet developed a classroom where all of students are using tablets along with the instructor. We have certainly discussed this scenario, the funding requirements and the other issues involved.

(2) Better Core Concept Presentation - ENGR 315 cash flow diagrams provide students with a picture of an engineering economics problem that shows all cash inflows and outflows plotted along a horizontal time line. It would be impossible to overemphasize the importance of helping students visualize these problems to determine the appropriate method of solution.

A shown in Figure 1 above, the instructor was able to produce cash flow diagrams more precisely and efficiently than using whiteboard or blackboard. This method also able directly demonstrates with the Tablet PC that all homework problems, unless otherwise directed by instructor, should follow the ENGR 315 Format. This is a simple and powerful point because the desired end result is duplicated in front of the student without translation from a board presentation. This format is similar to that used for most professional engineering work using engineering paper and is duplicated for all homework assignments. The instructor has attempted to use a straightedge against the screen at different times, but this has proved to be more frustrating than valuable to this point.

Students write only on the front side of the paper with the darker green grid on the back. They scan their homework solutions or complete them directly on their tablet, save as a PDF, and post their homework on the CMS for grading. The quality of their presentations have improved under the implementation of these requirements

(3) Increased Instructional Efficiency - Using a pen-based tablet PC eliminates some interruptions and distractions caused by physical transitions between whiteboards and the projector screen. Using one tablet, one pen, and one projector with lecture recording has simply proven more to be more efficient for us than cycling through whiteboards using several different colored markers, erasing the results, and still needing a projector for Excel ${ }^{\circledR}$, Power-point ${ }^{\circledR}$.

Students would often have questions just after the instructor has erased a solution. Now, we can scroll back up the screen and revisit the problem or review the lecture in real time.

(4) Enhanced Clarification - Using the tablet allows the instructor to quickly introduce color during live presentations that further improve understanding of ENGR 315 concepts and classroom discussions. As shown in Figure 5 below, the instructor can easily select among line weights, pen tips, colors, lasso material, erasers, highlighters, etc. in digital ink without leaving the program. This method facilitates a more seamless course material presentation than could be realized with the physical tools, allows the instructor to prioritize and highlight certain concepts, and clarifies important points through the use of different colors.

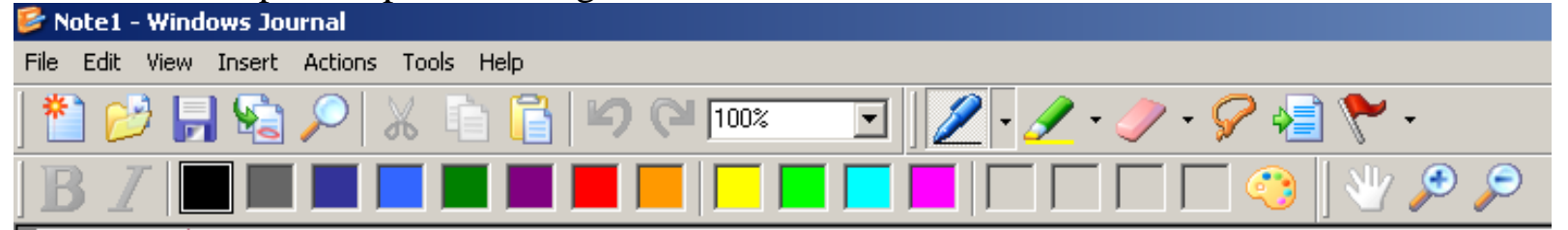

Figure 5 - Windows Journal Toolbars 
For example, the instructor might use green to denote positive cash flows and red to designate negative cash flows. One obvious advantage to the introduction of digital color as opposed to whiteboard markers is that the colors can be quickly changed or the highlighting might be quickly removed once that particular discussion point has passed.

In general, we have found that is helpful to introduce color to a cash flow diagram (CFD). This simple technique is relatively easy for an instructor using digital ink. Using several colors, we can essentially "color-code” diagrams to highlight certain relationships among different concepts discussed, and this appears to enhance the ENGR 315 students' comprehension of the material. While color-coding is certainly not a new concept, the relative ease, convenience, flexibility, physical familiarity, file storage, and accessibility of these applications is a recent development.

(5) Maintained Student Attention and Facilitated Note-taking - Using the tablet helps the ENGR 315 instructor incorporate and improve important course elements such as active student participation, dynamic visual aids, and color-coded illustrations into the lecture and course presentation. Utilizing these tools has helped engage students and increases the chance of holding their attention. This appears to be related to five different elements that have been observed during the incorporation of the tablet PC in the classroom.

- Student Participation - While facing the students, it is simply easier to encourage their participation by working examples and creating situations where students interact with each other and the instructor. For example, asking students to help develop the engineering economics problem example or scenario, interest rates, etc., and creating mini-labs where they work as single problem together as a small team competition. These simple ideas are not new, but once again, they are better facilitated by the technology and helps students share their ideas on how to solve a problem, engage them and create a more positive engineering problem solving atmosphere.

- Kinetic Presentation - Engineering students attend lectures to see instructors solve problems left-to-right and top-to-bottom. This centuries-old concept should not be forgotten in the Power-point ${ }^{\circledR}$ era. Digital inking better engages the student's kinetic senses because the instructor begins with the same blank slate that the student will be left with after class.

- Dynamic Lecture - "Working without a net" is encouraged by the technologies support for working problems, making mistakes, correcting mistakes, capturing the process. The instructor can learn more about methods that appeared to work best, review lectures that did not work very well, and explore the differences. At minimum, it is certainly an improvement over memorizing lectures or reading word-for-word from slides. In this experience, it has worked best to simply prepare a bulleted problem strategy list that outlines the issues that need to be addressed. Working from the tablet helps the instructor face students more naturally, maintain a conversation with eye contact, and better gage the student's reactions to the material presentation.

- Capture Examples - Effective study in ENGR 315 relies on revisiting examples and emphasizing main points in previous examples or illustrating alternative solutions. 
Scrolling backwards or reopening examples is a common technique that would not be possible if these problems had been erased from the whiteboard. Using the tablet in ENGR 315 helps the instructor stay on topic and clearly correlate problem examples with the main points of that the demonstration is attempting to convey to the student.

- Visual Elements - In addition to the variety of tools described earlier, another obvious benefit of working inside the tablet XP environment is that the instructor can utilize any other common extra visual element common to Windows ${ }^{\circledR}$ in the presentation. Website print screens can be captured and pasted in the notes, Excel ${ }^{\circledR}$-based solutions, calculators, and of course short video/audio clips can be placed alongside other visual materials in a context that helps emphasize the message of the presentation. When utilizing Power Point ${ }^{\circledR}$, digital inking directly on the slide keeps the original limited to a few points with plenty of white space for live augmentation. This process enlivens reliable tools and aides the instructor in presenting outlined material while maintaining immediacy in the content.

Ideally, instructors enjoy the idea of leaving some lasting impression on their students and must continue to explore methods for keeping their attention. By incorporating these elements into the presentation of ENGR 315, we have been able to improve the attention level of our students.

Directly linked to our capability to improve the student attention level, is that it facilitates student note taking through CART CMS posts that improve organization and elaboration. In other words, students can view, ink and print the instructor notes at will and augment the lecture notes with their own ideas and observations. According to the Northwest Educational Technology Consortium (NETC), Focus on Effectiveness, (http://www.netc.org/focus/strategies/summ.php), Summarizing and Note Taking:

"Effective summarizing leads to an increase in student learning. Helping students recognize how information is structured will help them summarize what they read or hear. For example, summarizing of a reading assignment can be more effective when done within summary frames, which typically include a series of questions the teacher provides to direct student attention to specific content (Marzano, Pickering, \& Pollock, 2001). Students who can effectively summarize learn to synthesize information, a higher-order thinking skill which includes analyzing information, identifying key concepts, and defining extraneous information.”

For ENGR 315, “summary frames” are literally marked by the divider lines in the lecture notes. Some students informally report that they would rather observe and listen to the lecture without taking any notes at all. Other students print the notes to keep in their notebooks to write on. Of course, a few students neither appear to pay attention or keep notes regardless of the methods employed. 
(6) Accommodated Student Review - ENGR 315 tests and quizzes are built directly from the lecture notes described above and are based on solutions to problems taken from the textbook for the course, which is currently Engineering Economy by Leland Blank, P.E., and Anthony Tarquin, P.E., 6th Ed. McGraw-Hill. 2005. The note keeping process described above is a related strategy that the instructor and students used to support student review for tests and quizzes. The explicit, inherent, and automated note-taking, ensures that all students have notes for certain. Rather than simply write down equations or record problems line for line, without any subsequent analysis. Successful students appear to have reviewed the posted notes and summarized the important elements to good effect. In total, students benefit from reviewing their notes as documentation of their learning. The instructor can call attention and prompt students to further review and refine their notes, particularly when it is time to prepare for a quiz or an exam.

(7) Higher Quality Student Portfolios - The ENGR 315 course site provides students with a ready-made, savable, printable, portfolio useful for Fundamentals of Engineering (FE) review and exam preparation. The online portfolio of scanned, saved, and uploaded homework, test results and notes, quizzes, forum discussions, questionnaires, and bonus assignments is worth up to $5 \%$ of the final course grade. The instructor can save off the entire course including all activities on a $\mathrm{CD}$. This proved useful during the TAC of ABET accreditation visit of our school programs during the fall semester 2010. Students can complete the course with a printed notebook portfolio and CD copy of their materials for future reference.

(8) Expanded Breadth of Coverage - Finally, the use of the tablet PC in ENGR 315 enabled the instructor to work more high-quality problem examples due to these increased course delivery efficiencies. The technology seems to have allowed the instructor to cover a small amount of extra material, perhaps gaining a session or two in the pacing, without any recognizable detriment the course. It is probably too early to determine if this is a permanent result.

\section{Conclusions}

- Pen-based technology improved the learning environment for ENGR 315

- The impact of using pen-based technology in ENGR 315 can be measured by an increase in overall student satisfaction with the course and deserves further analysis..

- The convertible tablet is more useful for ENGR 315 than the slate form factor.

- Based on recent experience with pen-based technologies in ENGR 315, the instructor now uses this method in other courses, recommends this learning environment to colleagues, and is experimenting with new technology as part of the continual improvement process.

- All ENGR 315 students (and possibly all School of Engineering Technology students) need to use pen-based tablet technology in this (these) course(s). 